\title{
Function Design on Educational Administration Management System
}

\author{
Zhe $\mathrm{Li}^{1, \mathrm{a}}$, Hui Ma ${ }^{2, \mathrm{~b}}$ \\ ${ }^{1}$ College of International Exchange, Bohai University, Jinzhou, 121013, China \\ ${ }^{2}$ School of Mathematics and Physics, Bohai University, Jinzhou, 121013, China \\ a503412508@qq.com, bhuima2016@163.com
}

\begin{abstract}
Keywords: educational administration management system; function design; modularization;
\end{abstract} function structure

\begin{abstract}
Educational administration management system, comply with the development of higher education cause, unified teaching resource management, standardize business processes, reduce labor intensity and enhance the level of teaching management. In view of the difficulties in system development, this article is based on modular design ideas, using heuristic strategies for function. Design results using module chart says, and the each subsystem are described. Mainly includes: Integrated information portal subsystem, Student information management subsystem, Teacher information management subsystem, School roll changes management subsystem, Semester registration management subsystem, Degree qualification management subsystem, Course resource management subsystem, Teaching plan management subsystem, Teaching task management subsystem, Course arrange management subsystem, Student elective management subsystem, Examination management subsystem, Experimental teaching management subsystem, Test score management subsystem, Teaching quality monitoring subsystem, Teaching material management subsystem, Network teaching evaluation subsystem, Web query service subsystem, Basic information management subsystem and System configuration maintenance subsystem.
\end{abstract}

\section{Introduction}

Educational work is an important work of normal operation and development of the school, is directly related to the daily teaching education go smoothly. Educational administration personnel is an important implementers, propulsion of education informationization is the backbone of the construction of digital campus, and is implement and realize the explorer and pioneer of education teaching reform. With the deepening of the reform of education system, increasing the number of students, curriculum development, to the depth and breadth also from academic year system to credit system teaching system, the original educational administration system is more and more cannot satisfy the need of modern educational administration of colleges and universities. To raise the level of educational administration, it is necessary to update management idea, strengthen the scientific understanding of management activities. To use advanced information technology, the integration of more advanced teaching management concept, the development of intelligent degree of the modernization of higher educational administration management system, deepen the reform of educational administration system is the favorable measures.

System function is a major means of completing the user needs, functional design is an important work in software development, function design must follows the thought of modularization. Modular refers to solve a complex problem step by step a top-down process of divides the system into several modules, a variety of properties, reflect its internal characteristics respectively. Modularization is used to break up, organization and packaged software. Each module completes a specific function, all modules assembled by some methods, as a whole, to complete the required whole system function. In the structure of the system, modules can be combined, decomposition and replacement of the unit. Modularity is a complex system is decomposed to become better to management module. By setting up different functions in different components, dividing a problem into many small independent and interact with each other component, to deal with the complicated large software. 


\section{System Function Structure}

Educational administration management system involves the students graduate from school to the whole process of management, including student management, teaching plan, course management, process management, course management, performance management, experiment management, graduation design management and the teaching quality monitoring management, and other links. Following the function of the modular thought design result usually use hierarchical diagram.

Preliminary results from a functional design to use heuristic design strategy was improved, some common heuristic design strategy has the following: transform software structure, reduce the coupling, enhance cohesion; To reduce the fan out, the pursuit of high fan-in; Make the scope of any module in the control domain; Reduce the module interface complexity and redundancy, improve coordination; Predictable module function, to avoid too many restrictions on the module; The pursuit of the single entry, the export module; To meet the requirements of design and portability, and use some software package is encapsulated; In the process of the choice or "monotonous" module should exist alone, in order to be efficient and load. Primary subsystem design, this article only the function of the subsystem is the design content of the next step. Functional design results are shown in Fig. 1.

\begin{tabular}{|c|c|}
\cline { 2 - 2 } \multicolumn{1}{c|}{ Educational Administration Management System } \\
\hline Integrated information portal subsystem & Student elective management subsystem \\
\hline Student information management subsystem & Examination management subsystem \\
\hline Teacher information management subsystem & Test score management subsystem \\
\hline School roll changes management subsystem & Teaching quality monitoring subsystem \\
\hline Semester registration management subsystem & Teaching material management subsystem \\
\hline Degree qualification management subsystem & Network teaching evaluation subsystem \\
\hline Course resource management subsystem & Web query service subsystem \\
\hline Teaching plan management subsystem & Basic information management subsystem \\
\hline Teaching task management subsystem & System configuration maintenance subsystem \\
\hline Course arrange management subsystem & Seming management subsystem \\
\hline
\end{tabular}

Fig. 1. Function Design on Educational Administration Management System

\section{System Function Description}

For each subsystem is shown in Fig. 1 of educational administration management system functional description is as follows:

(1) Integrated information portal subsystem, web portal, is to point comprehensive Internet information resources and provide relevant information service application system. Comprehensive information portal within the campus network on information and management and application system integration, unified control user access to information and application system, provide users with integrated access. At the same time, according to the user's identity for meet the demand of the specific information and application of the system, to provide users with personalized service.

(2) The Student information management subsystem, information updates quickly, easy management, function setting reasonable Student information management solutions, to provide an interactive platform for the Student management information. Implement the management and maintenance of the basic information of the students, all kinds of information query and statistics. System goal is as follows: the student information management more scientific; Provide flexible 
and convenient operation; To save the cost of student information management, improve the efficiency of management; For the system to provide the necessary permissions management.

(3) The Teacher information management subsystem, information of teachers is the main resource of school, as an important application system in education informationization, to improve school teaching, scientific research and management environment, the basis of solving various problems existing in current Teacher information management, reduce burden of educational administration personnel, promote the school management modernization level of ascension. Requires the application functional, meet the needs of management, namely the realization of teacher's information to add, modify, delete, announcement, file upload download, user permissions Settings, and other functions.

(4) the School roll changes management subsystem mainly USES the student management in colleges and universities work including spreadsheets, superior issued registration management system, the general type management system, etc. these are insufficient or there is a certain limitation, unable to meet the needs of comprehensive management. Notebook system including system management, student status management, in (registration, registration), data management, data statistics, decision support, such as function modules, use network technology to realize data sharing, real-time online secondary college to participate in management.

(5) Semester registration management subsystem. The implementation of students register of all business data management, report such as single, charge records, ticket information and basic data information management and maintenance. Ensure that students register link of normative, reducing the error. To strengthen the process control of register, sign in link not completed, will not be able to enter the payment link, payment link did not complete, cannot complete all the rest of the other links

(6) Degree qualification management subsystem. According to the corresponding format is flexible in the second Degree diploma number, card number, card number automatic choreography; Administration may authorize the corresponding unit of secondary teaching graduate and degree qualification; The financial department to supervise and control the students pay cost and student loans; The Xinhua electronic picture import book system, the acquisition of individual students can also photo.

(7) Course resource management subsystem. The basic information maintenance and management of the courses, provides the basic data to other modules or subsystems. Course data may be passed by the office of management personnel authorized by the secondary teaching unit of input, modify, query; Provide school history course information with the open information management, respectively; student course selection condition in each course in order to make students better understand the information, provide relevant course introduction, teaching outline, and exam outline published in campus network.

(8) Teaching plan management subsystem, support academic year system, credit system and academic year credit system school-running idea. Provide the school public course selection information maintenance; Provide various professional graduate qualification audit condition maintenance; Provide professional training scheme and process teaching plan management; Replication to provide teaching plan, the same two annual teaching plans were similar, can be copied by the teaching plan, and then adjusted the details of the workload and reduce the input error probability. Professional introduction, professional training scheme, teaching plan and process web client.

(9) Teaching task management subsystem. Of the practical Teaching task for unified management of the term, unit of each course to undertake way through the network online submission or modify Teaching tasks, in order to avoid inconsistent Teaching task and Teaching plan, provide automatic generating Teaching task functions according to the Teaching plan. Teaching task most data provided for the secondary teaching unit, due to factors such as time, school distribution and venue for has a great influence on curriculum arrangement, system aimed at this situation consider providing teaching task accuracy, rationality of calibration function and the corresponding recommended solutions. 
(10) Courses arrange management subsystem. The curriculum is one of the most important part of educational administration work, is also the most complicated and tedious work. Constantly expanded in the teaching and teaching resources increasingly tense situation, in the process from manual to automatic computer course arrangement is the urgent requirement of educational administration work. Distributed curriculum arrangement, office of public courses, the college arrange professional course; The process for different types of courses can be set automatically according to the circumstance priority; Processing a variety of complex scheduling; The user can directly by dragging operations to manually adjust the timetable.

(11) Student elective management subsystem. Provide professional online selection and direction on course of study in different professional direction course requirements, control and management service for the students' online courses. Course selection system is a comprehensive educational administration system is one of the important and difficult. To make the necessary preparations before choosing courses; Course selection in the process of real-time monitoring, and can be adjusted according to the actual register temporary; After course should be arranged according to the result of course resources and track the improvement of students; For across the semester elective courses, provide replication course selection list.

(12) Examination management subsystem. At the end of each semester students' academic examination to test study effect. Educational administration department in the test involves a lot of preparation work, such as arrange the test and the supervisor, to ensure the smooth progress of the examination. This notebook system implementation organization works for informatization and automation. Support course examination and registration; Support rebuilding, grace and make-up examination; The science and rationality of the examination room arrangement, The test time to events as the arrangement of unit; Easy to test and the teaching time and coordination; Manually adjusted according to actual situation.

(13) Experimental teaching management subsystem. Through the experiment students can choose according to their own free time to make an appointment experiment courses. According to different experimental laboratory equipment management to provide the same laboratory projects at the same time, realize the students' free time and make the best use of laboratory resources. Realize the open laboratory management, students according to the teaching schedule appointments experiment on the Web end. Students also can choose according to their own interests experimental subjects. Unified management of equipment and consumable, and the system automatically according to the priority level of student subject choice.

(14) Test score management subsystem. The Test scores is to examine the effects of teacher's teaching effect and students' learning important measures, and examination of the important basis of degree. Performance management is accuracy and safety. System provides three types of entry mode: the teacher can enter this student performance classes, teaching secretary can entry the college student achievement, director of the teaching and research section can be recorded in the present teaching and research section of courses grades; English cet 4 and cet6, computer grade examination results management functions, and is associated with student data in the audit; After the completion of the offering achievements recorded voice proofreading function; Provide performance auditing.

(15) Teaching quality monitoring subsystem. The Teaching quality monitoring including Teaching management, Teaching process and the content of the Teaching object, etc. Teaching management monitoring content reflects the requirement for the quality of teaching and school standards. Monitoring content of the teaching process, and reflects the teacher's teaching work on the subjective initiative, predominant embodies the teaching quality. Monitoring contents of teaching object, reflects the students' learning subjective efforts and the objective environment, embodies the teaching quality of formation of the main aspects.

(16) Teaching material management subsystem. Teaching material is a tool for students learning and reference, is one of the important content of Teaching management. Teaching material selection, reservation, equipped with, and teaching evaluation are working contents of teaching material management. Teachers can determine the personal home page teaching material types; Students in 
the personal home page for order confirmation and teaching material receiving situation query; Teaching and research section, students, teachers, class, give a variety of ways, such as retail and warehouse management; Through distribute rate of teaching materials, teaching material usage and questionnaire statistics to implement the basic teaching material evaluation.

(17) Network would evaluation subsystem, geared to the needs of teaching unit, used for students to teachers, teachers of teachers, leading to teacher's teaching evaluation. Provide quantitative and qualitative evaluation appraisal function. Can be a rating scale, can also be a digital scale; Scale conversion for actual scores can also be set according to the circumstance conversion system; Use the browser to collect the data of evaluation, and evaluate the automatic statistics; Combined query evaluation and performance and system log, to improve students' evaluation for teachers participation; Teachers through a web client queries for my teaching evaluation results.

(18) Web query service subsystem, the educational administration work of all kinds of information release to different levels of users, make the school staff and students can understand and grasp the dynamic teaching work. Generative can query this semester class schedule, your student records, rewards and punishments, accumulative total credits, and academic performance; Teachers can query individual participating class teaching commitments, curriculum, student status data; School leaders can query the entire school teachers' teaching task, the school each class and each course curriculum, department of the university students' enrollment, student status information and academic performance.

Basic information management subsystem and System configuration maintenance subsystem is management information System of general function, no longer described here.

\section{Conclusion}

The application of educational administration system, conform to the needs of the development of higher education cause, unified teaching resource management and standardize the needs of the business process, improve teaching management level, reduce the intensity of labor to build a virtual university space to achieve cross-regional management needs, provide "one-stop" service for staff and students. In this paper, the design of the achievement, solve the management of teaching is the key issues in system development, the actual development time according to actual needs to extend, in order to improve the adaptability.

\section{References}

[1] B. Xiang, X. H. Dong, H. Huang, "The Design and Realization of the Teaching Integrated Information Management System," Computer Knowledge and Technology, vol. 12, no. 17, pp. 78-81, 2016.

[2] C. C. Xu, "The Design and Implementation of Educational Management System under the Framework of SSH," Journal of Tongren University, vol. 18, no. 4, pp. 85-87, 2016.

[3] H. Chen, "The function optimization analysis of university educational administration management system," Education Modernization, vol. 2, no. 15, pp. 164-165, 2015.

[4] Z. M. Li, "The architecture design of the credit system educational administration management system based on B/S," Fujian Computer, vol. 31, no. 3, pp. 91-93, 2015.

[5] W. Lan, "The development of college educational administration system based on the framework of SSH2," Journal of Chongqing University of Arts and Sciences (Social Sciences Edition), vol. 35, no. 5, pp. 108-112, 2016.

[6] X. W. Chen, "Design and implementation of educational administration system in Colleges and Universities," Journal of Hunan City University (Natural Science), vol. 25, no. 3, pp. 87-88, 2016.

[7] Y. H. Zhang, "Design of the Educational Administration System Based on .NET Framework," Computer Knowledge and Technology, vol. 11, no. 8, pp. 14-15, 2015. 